\title{
Tropical pacific forcing of a 1998-1999 climate shift: observational analysis and climate model results for the boreal spring season
}

\author{
Bradfield Lyon • Anthony G. Barnston • \\ David G. DeWitt
}

Received: 10 April 2013/ Accepted: 16 July 2013/Published online: 26 July 2013

(C) The Author(s) 2013. This article is published with open access at Springerlink.com

\begin{abstract}
Observational data and climate model simulations and experiments are utilized to document an abrupt shift in Pacific sea surface temperatures (SSTs) and associated atmospheric conditions, which occurred in 1998-1999. Emphasis is placed on the March-May (MAM) season, as the motivation for the work is to extend a recent study that reported an abrupt decline in East African MAM rainfall at that time. An empirical orthogonal function analysis of MAM SSTs over the last century following the removal of the concurrent influence of the El Niño-Southern Oscillation and global warming trend by linear regression reveals a pattern of multidecadal variability in the Pacific similar to the Pacific Decadal Oscillation. Examination of MAM precipitation variations since 1940 indicates, among other findings, that recurrent drought events since 1999 in East Africa, central-southwest Asia, parts of eastern Australia and the southwestern US are all regional manifestations of a global scale multidecadal pattern. Associated shifts in the low-level wind field and upper-level stationary waves are discussed. Simulations using an atmospheric climate model forced with observed, global SSTs capture many of the salient precipitation and atmospheric circulation features associated with the observed shift. Further, when the model is forced only with observed SSTs from the tropical Pacific it also captures many of the observed atmospheric changes,
\end{abstract}

\footnotetext{
B. Lyon $(\bowtie)$ · A. G. Barnston · D. G. DeWitt

International Research Institute for Climate and Society,

The Earth Institute, Columbia University, 61 Route 9W,

Palisades, NY 10964, USA

e-mail: blyon@iri.columbia.edu

Present Address:

D. G. DeWitt

NOAA/NWS, Washington, DC, USA
}

including the abrupt shift in 1999. The results point to the fundamental role played by the tropical Pacific in driving the response to multidecadal variability of SSTs in the basin and provide important context for recent seasonal climate extremes in several regions of the globe.

Keywords Climate shift - Decadal variability . Pacific · Drought · East Africa

\section{Introduction}

In this study we document a shift in Pacific sea surface temperatures (SSTs) in 1999 associated with multidecadal variability and summarize some of its associated changes in regional climate around the globe. The study first utilizes observational analyses of SSTs, precipitation and atmospheric data from reanalysis products to identify the main characteristics of this shift and place it in historical context. Climate model simulations and idealized model experiments are then employed to show the role of SSTs, particularly in the tropical Pacific, in forcing the observed atmospheric changes. The focus is on the three-month season of March-May (hereafter MAM, other seasons similarly denoted) and the near-global domain. The motivation for this work was a recently published study that reported on an abrupt decline in the MAM "long rains" in East Africa that occurred around 1999 (Lyon and DeWitt 2012; hereafter LD). In that study, the shift towards decreased long rains precipitation was linked to similarly abrupt and nearly synchronous changes in SSTs in the tropical Pacific, although a detailed analysis of the SST changes was not provided. What LD did show was that the decline in MAM rainfall across East Africa was part of a recurrent, large-scale precipitation anomaly pattern that 
extended across the Indian Ocean into the Pacific during the post-1998 period. The abrupt shift in East African rainfall and its connection to a recurrent, large-scale precipitation anomaly pattern suggests that decadal variability may indeed be playing a role.

Here we extend the work of LD to examine in more detail the nature of the large-scale shift in SST in 1999 and the associated atmospheric circulation and seasonal precipitation patterns around the globe during the MAM season. It is shown that the identified shift in the Pacific is akin to the widely analyzed 1976-1977 climate shift (Tenberth and Hurrell 1994; Graham 1994 and many others). While some studies have suggested a climate shift in the Pacific may have occurred in the late 1990s (e.g., Bond et al. 2003; Chavez et al. 2003; Peterson and Schwing 2003), it has also been argued by some investigators that these recent changes are not well captured by a shift in any single indicator, such as the Pacific Decadal Oscillation index (PDO; Bond et al. 2003; Merrifield 2011). More generally, Deser et al. (2004) advocate the use of multiple indicators when assessing interdecadal climate variations in the Pacific. In the current analysis we do not restrict ourselves to the examination of the PDO and unlike previous studies, which have generally emphasized the boreal cool season (typically NDJFM, or DJF) when examining climate shifts such as in 1976-1977, here we focus on the MAM season, which has received comparatively little attention from researchers. And yet, in many locations the MAM season is very much of interest: it is central to the East African long rains with the end of that season immediately proceeding the onset of the South Asian summer monsoon, as just two examples from around the globe.

Given the global scale of the atmospheric response to the climate shift investigated here, it will not be possible to provide detailed descriptions of the mechanisms associated with the regional circulation and precipitation changes that have occurred during the post-1998 period. Instead, the overall goal of the study is to provide an overview of the salient features in large-scale patterns of SST, precipitation and atmospheric circulation variations associated with the 1999 shift in the Pacific. Additional work will be required to gain a better understanding of the physical mechanisms at play in driving specific regional climate changes around the globe. Here, emphasis is placed on demonstrating that the background state of SSTs in the east-central Pacific has cooled by over $0.5^{\circ} \mathrm{C}$ since 1998 and that SST changes in the tropical Pacific are central in driving the regional climate changes that have occurred since that time. This latter conclusion is based on climate model experiments where the model forcing is from observed SSTs limited to the tropical Pacific Ocean domain (POGA runs) revealing a common contribution, for example, to recurrent droughts in East Africa, central-southwest Asia and the southwestern US.
In addition, in contrast to previous studies which have emphasized large-scale circulation changes mainly over the central and eastern North Pacific during boreal winter associated with multidecadal Pacific variability (e.g., Trenberth 1990; Tenberth and Hurrell 1994; Zhang et al. 1996; Minobe 1997; Zhang et al. 1997), here an important finding is the identification of a recurrent wave train that extends from the western tropical Pacific into both northern and southern hemispheres during the post-1998 period. Some of the results presented here also support the idea of a Pacific multidecadal modulation of the onset of the South Asian summer monsoon as reported in a recent study by Xiang and Wang (2013).

The paper is outlined as follows. In the next section the observational and model data sets used in the study are described and a discussion of the overall methodological approach is provided. In Sect. 3 observed changes in SSTs, precipitation, and various aspects of the atmospheric circulation are examined, while Sect. 4 focuses on the ability of climate model simulations and POGA experiments to capture the observed shifts. A summary of the overall findings and the main conclusions drawn from the study are provided in Sect. 5 .

\section{Data and methodological approach}

\subsection{Observational data}

Gridded monthly precipitation analyses for global land areas contained in the Global Precipitation Climatology Center version 6 (GPCC; Rudolf and Schneider 2005) dataset are utilized. This dataset is derived solely from station observations. Merged satellite-gauge precipitation estimates from both the Global Precipitation Climatology Project version 2.2 (GPCP; Huffman et al. 2009) and the US Climate Prediction Center merged analysis of precipitation version 2.1 (CMAP; Xie and Arkin 1997) are also analyzed. The spatial resolution used for all three of these datasets is $2.5^{\circ}$ latitude $\times 2.5^{\circ}$ longitude, with an analysis period of $1940-2010$ used for GPCC (data in version 6 ends in 2010), 1979-2009 for GPCP and 1979-2011 for CMAP. As the CMAP data extends closer to the current time than does GPCP, only results from the former are presented here but they were closely compared with those from GPCP, as will be discussed. Monthly average outgoing longwave radiation (OLR) data from the US Climate Prediction Center (CPC) covering the period 1979-2013 were utilized and were accessed via the data library at the International Research Institute (IRI) at: http://iridl.ldeo.columbia.edu/SOURCES/. NOAA/.NCEP/.CPC/.GLOBAL/.monthly/.olr/. These data are at a $2.5^{\circ}$ latitude $\times 2.5^{\circ}$ longitude resolution. Monthlyaveraged fields of various atmospheric variables contained in the National Centers for Environmental Prediction Reanalysis-2 product (hereafter, R2; Kanamitsu et al. 2002) and the 
Twentieth Century Reanalysis Project (20CR; Compo et al. 2011) were employed. R2 data covered the period 1979-2012 and for 20CR data for the period 1930-2008 was used, with $\mathrm{R} 2$ at $2.5^{\circ}$ and $20 \mathrm{CR}$ at $2.0^{\circ}$ latitude $\times$ longitude resolution. The use of $\mathrm{R} 2$ rather than the longer reanalysis- 1 data is because of concerns regarding consistency of fields in the pre- versus post-satellite era in the latter. To extend the analysis in the time domain, 20CR data are used, which is based only on assimilated sea level pressure observations while having the added benefit of extending further back in time than R2. Gridded monthly SST data were obtained from the Extended Reconstructed SST version 3b dataset (Smith and Reynolds 2003) and the hadley center SST and ice extent product (HADISST; Rayner et al. 2003). The spatial resolutions are $2.0^{\circ}$ and $1.0^{\circ}$ latitude $\times$ longitude for the ERSST and HADISST datasets, respectively. The period of analysis for both the ERSST and HADISST products was 1900-2012.

\subsection{Climate model simulations and experiments}

The climate model utilized is the ECHAM4.5 (Roeckner et al. 1996) atmospheric model from which an ensemble of 24 members was generated (using slightly different initial atmospheric conditions) for the "full simulation" runs where the model was forced with observed, global SSTs. Previous work by LD found this model performs well in simulating the MAM seasonal climate in the East African and southern Asian regions and it is one of models included in the multi-model ensemble of the IRI for its regular production of monthly seasonal forecasts for the globe. For the POGA runs the model was forced with observed SSTs only for the tropical Pacific $\left(25^{\circ} \mathrm{S}-25^{\circ} \mathrm{N}, 120^{\circ} \mathrm{E}-80^{\circ} \mathrm{W}\right)$ domain using slightly different initial atmospheric conditions to generate an ensemble of 30 members. For the POGA runs, a slab ocean model was run outside the tropical Pacific domain such that SSTs could respond thermodynamically to the overlying atmosphere. The slab ocean model contains no ocean dynamics, which can have adverse effects in simulating the Pacific cold tongue, for example. To address this issue a set of specified surface flux adjustments ("qflux") are incorporated in the model and applied at each time step of the integration in order to keep the SST annual cycle close to that found in observations. For both the full simulations and POGA runs, the horizontal resolution of the model was roughly $2.8^{\circ}$ latitude $\times$ longitude (a T42 spectral truncation was used) and only monthly average values of model output fields were incorporated in the study.

\subsection{Methodological approach}

Recurrent anomaly patterns in various fields were identified mainly through the use of compositing and empirical orthogonal function (EOF) analysis. Anomalies were defined as the difference from various base period averages, which are described in specific contexts in the text. Two sample t-tests were applied to determine the statistical significance of composite anomalies and in differences between time-mean values in principal component (PC) time series. As there is an a priori expectation that the recent shift should favor a particular sign of anomalies, statistical significance is based on a one-tailed test unless otherwise noted in the text. As the focus of the study is not on the direct influence of ENSO or long-term trends of SSTs, in the analysis these two influences were first removed from the full SST field by linear regression techniques in both the ERSST and HADISST datasets. In this approach, a nearly global average SST anomaly (base period 1971-2000) time series covering the period 1900-2012 for the MAM season was first generated for each dataset by averaging all grid point anomaly values between $55^{\circ} \mathrm{S}$ and $55^{\circ} \mathrm{N}$ after weighting by the cosine of the latitude. An ENSO time series was next defined as the sum of the first two PCs from an EOF analysis of MAM tropical Pacific SST anomalies (1971-2000 base period) applied over the domain $125^{\circ} \mathrm{E}-75^{\circ} \mathrm{W}, 15^{\circ} \mathrm{S}-15^{\circ} \mathrm{N}$. The first two EOFs combined account for 42.1 and $45.8 \%$ of the total SST variance in the HADISST and ERSST datasets, respectively and the temporal correlation between our ENSO time series and a Niño3.4 $\left(5^{\circ} \mathrm{S}-5^{\circ} \mathrm{N}, 170^{\circ} \mathrm{W}-120^{\circ} \mathrm{W}\right.$ average) SST anomaly index was $>0.92$ for both datasets. The MAM SST anomalies at each grid point in the ERSST and HADISST datasets were then regressed onto the global SST and ENSO time series, with the regressed values then subtracted from the full anomaly field to yield a residual MAM SST anomaly field covering the period 1900-2012. No temporal filtering was applied to either SST dataset in this analysis. It is also emphasized that the linear removal of the long-term warming signal and ENSO was only done for the SST data. A similar regression method was not applied to the other observed or modeled atmospheric fields used in the study.

There are a few caveats to this approach. First, ENSO events evolve in time and space (e.g., there are lagged responses to ENSO in the SST of the Atlantic and Indian oceans) making their removal from the SST time series (by linear regression or any other method) challenging (e.g., Compo and Sardeshmukh 2010). In addition, some studies (e.g., McPhaden et al. 2011; Hu et al. 2013) suggest that multidecadal Pacific SST variability results from a rectification of ENSO-related SST anomalies. In this view, the recent cooling in the central Pacific since 1999 would be attributed to an increased frequency of La Niña events in recent years. Relatedly, linear removal of ENSO from the SST data could affect any lower frequency variability that is identified in our residual SST field (Newman et al. 2003). For example, the PDO index as defined by Mantua et al. 
(1997) shows a modest correlation with ENSO indices on the seasonal time scale. In terms of the first issue, while we recognize that ENSO is an evolving physical process, the emphasis here is on a single season with MAM typically representing a period during which the ENSO signal is comparatively weak. In terms of ENSO and the PDO, obviously only the simultaneous relationship between global SSTs and ENSO is being removed in our linear regressions. And while this may indeed weaken any PDO signal present, the emphasis of this study is not on the PDO but rather on decadal scale variability of SSTs that may very well be correlated with the PDO. As will be shown in Sect. 3.2, this is indeed found to be the case.

\section{Recent observed changes and the 1999 shift}

\subsection{Observed changes since 1998}

Despite a general warming trend in many areas of the world's oceans over the past six decades (e.g., Compo and Sardeshmukh 2010), based on the total ERSST dataset anomalies (i.e., not the residual SST field), MAM SSTs in parts of the east-central tropical Pacific averaged over the period 1999-2012 have been more than $0.5^{\circ} \mathrm{C}$ cooler than the 1977-1998 average (Fig. 1a). The pattern of extratropical North Pacific SSTs, with positive SST anomalies in the west and negative anomalies in the east is indeed reminiscent of a PDO structure, with the largest amplitude anomalies located in the extratropics (Zhang et al. 1997). The positive anomalies in the western North Pacific are part of a horseshoe shaped pattern that extends into the southern hemisphere. The positive SST anomalies in the North Atlantic Ocean during 1999-2012 include the effect of a shift towards the positive phase of the Atlantic multidecadal oscillation around 1995 (Enfield et al. 2001). SST changes in the tropical Indian Ocean since 1998 are comparatively modest.

The difference in average MAM seasonal precipitation between 1999-2011 and 1979-1998 (shading in Fig. 1b; only statistically significant values plotted, $p<0.10$ ) as revealed in the CMAP data shows several large-scale features. Consistent with LD who used the GPCP data, East Africa has been much drier, as has portions of centralsouthwest Asia, the central and southern Indian Ocean, portions of eastern Australia, the tropical central and eastern Pacific and the southwestern US. Prominent areas with wetter conditions include northern South America and a zonally elongated band extending across the northern Indian Ocean into the Philippines and the western tropical Pacific. Results based on the GPCP data (which ends in 2009) are very similar (not shown). As a proxy for precipitation changes over the tropical Pacific and Indian oceans, Fig. 1c utilizes the CPC OLR data, denoting where the average MAM values equal $230 \mathrm{Wm}^{-2}$ for the period 1999-2013 (blue line) versus 1979-1998 (red line). The panel indicates that the region of heaviest precipitation in the equatorial central Pacific has shifted westward by roughly $10^{\circ}$ longitude since 1998, with a southwestward shift in precipitation associated with the south Pacific convergence zone (SPCZ) as well. There has been a northward shift in precipitation in the western Pacific into the eastern Indian Ocean. Similar results were again found for the GPCP and CMAP data. These general shifts were also identified when the major El Niño events during MAM 1983 and MAM 1998 were omitted from the analysis of the OLR data (with generally similar results again for CMAP and GPCP data).

The vectors plotted in Fig. $1 \mathrm{~b}$ are the anomalies of the $850 \mathrm{hPa}$ horizontal wind (only statistically significant values are shown, $p<0.10$ ) defined as the difference in the average for 1999-2012 minus 1979-1998 based on R2. Anomalous easterlies are seen across the tropical central and western Pacific with anomalous westerlies across the northern Indian Ocean, the combined effect being anomalous convergence into the western Pacific region of enhanced precipitation. An anomalous anticyclonic circulation near and to the southeast of the Aleutian Islands is evident over the North Pacific. As shown by LD, anomalous southeasterly winds across the southern Indian Ocean re-curve and form a cross-equatorial southerly flow in the western part of the basin off the east coast of Africa. The main features shown in Fig. 1 will be elaborated upon in subsequent sections of the study where they will be placed into the context of multi-decadal variability in the Pacific.

As one indication of why the post-1998 period is of interest, Fig. 2 shows the loading pattern and associated PC time series for the leading EOF of MAM precipitation anomalies for the period 1979-2011 in the CMAP data. The loading pattern very nicely aligns with the precipitation anomaly pattern shown in Fig. 1b with the PC time series showing a clear shift in 1999. Indeed, the difference between mean values of the PC time series for the periods 1979-1998 and 1999-2011 is statistically significant at $p<0.01$. Similar results were found using the GPCP data, with a pattern correlation of the EOF loadings between CMAP and GPCP of 0.93 and a temporal correlation between the respective $\mathrm{PC}$ time series of $\mathrm{r}=0.99$. The abrupt shift in 1999 is also seen in the GPCP data, again suggestive of decadal scale climate variability.

\subsection{Multidecadal variation of the residual SST field}

To place the post-1998 climate changes into a longer time frame of variability, the MAM residual SST anomaly fields (i.e., obtained by linearly removing the global warming and ENSO signals via regression) in the ERSST and HADISST 
Fig. 1 a Difference in average MAM SST (deg. C) for 1999-2012 minus 1977-1998 based on the ERSST dataset. b Statistically significant $(p<0.10)$ precipitation differences for MAM 1999-2011 relative to 1979-1998 (mm/day; shaded) based on CMAP and $850 \mathrm{hPa}$ vector wind anomalies from $\mathrm{R} 2$ $\left(\mathrm{ms}^{-1}\right.$; scale vector at lowerright of plot) for the same period. c Regions where the average MAM OLR equals 230 $\mathrm{Wm}^{-2}$ for the periods 1979-1998 (red line) and 1999-2011 (blue line)
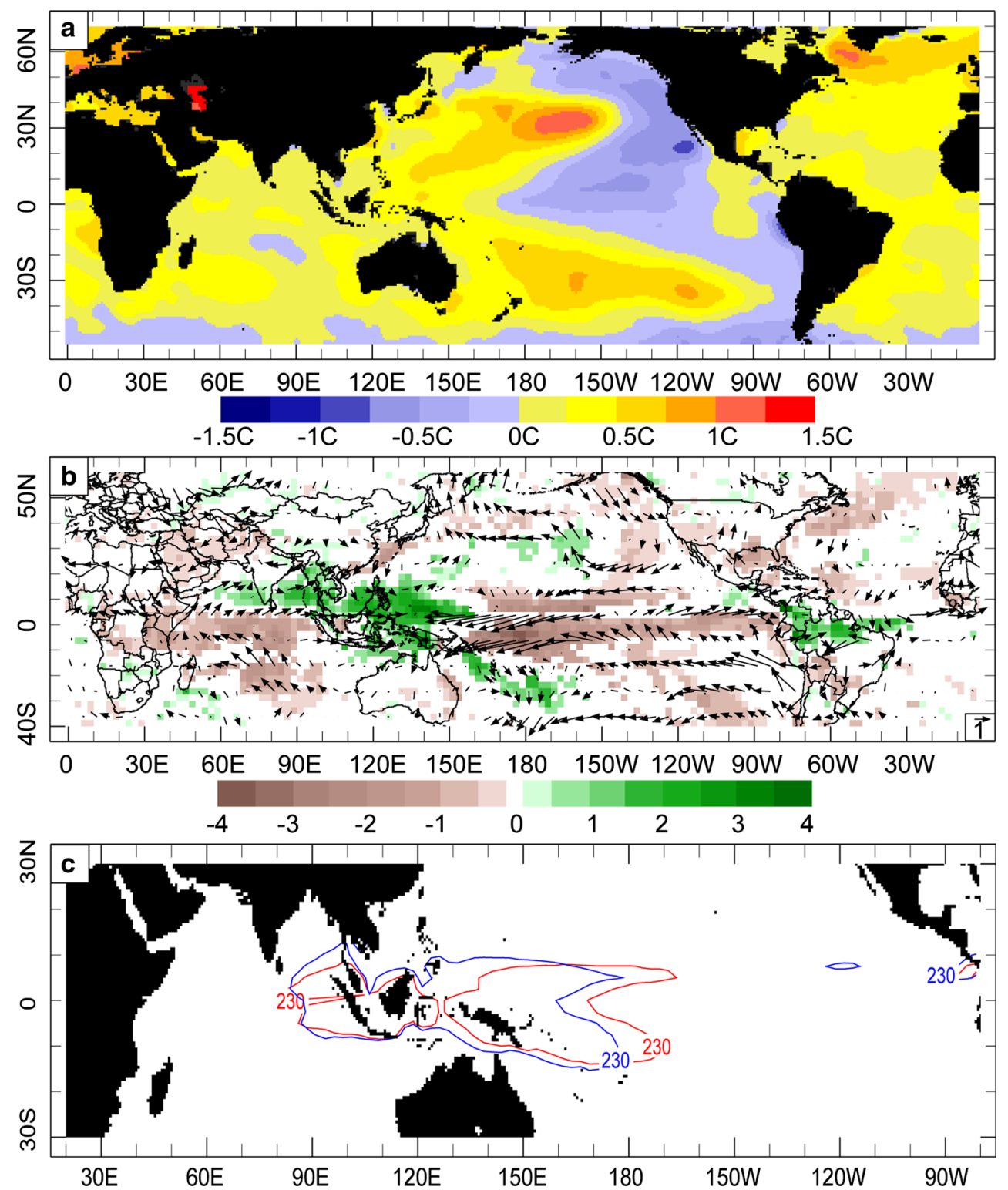

were analyzed over the period 1900-2012. The results were very similar for the two datasets so only those based on the ERSST are shown here. First, an EOF analysis was applied over the Pacific Ocean domain from $40^{\circ} \mathrm{S}-60^{\circ} \mathrm{N}$ and $120^{\circ} \mathrm{E}-80^{\circ} \mathrm{W}$, with the loading pattern for the leading mode (accounting for $18.3 \%$ of the variance) shown in Fig. 3a. The loading pattern in the North Pacific is very similar to that of the PDO, with a zonally elongated band of positive loadings extending from near Japan eastward to the central part of the basin and loadings of opposite sign off the west coast of North America extending southwestward towards the equator. The magnitude of the loadings is generally smaller in tropical areas. As mentioned, results were similar for HADISST with the pattern correlation between the leading EOF loadings for the two datasets equal to 0.90 .
The loading pattern over the Pacific is little changed if the domain is expanded to include the Indian Ocean as seen in the results for the leading mode (accounting for $15.3 \%$ of variance) in Fig. 3b. Note that negative loadings now also cover most of the Indian Ocean domain. Overall, the behavior in the Indian and Pacific Oceans is consistent with previous studies of the PDO (Liu 2012; Deser et al. 2004), where the sign of SST anomalies in the Indian Ocean for a given phase were found to be the same as those in the eastcentral Pacific. These results are also consistent with LD who emphasized a cooler eastern tropical Pacific and warmer western Pacific in the post-1998 period. Note that such a pattern is found here even when the global warming trend and ENSO have first been removed from the data. When the correlation matrix is used instead of the covariance matrix in the EOF analysis of the residual SST field 
Fig. 2 a Loadings (dimensionless) of the leading EOF computed for MAM CMAP precipitation over the period 1979-2011. b Associated PC time series. Horizontal dashed lines indicate mean values for the periods covered
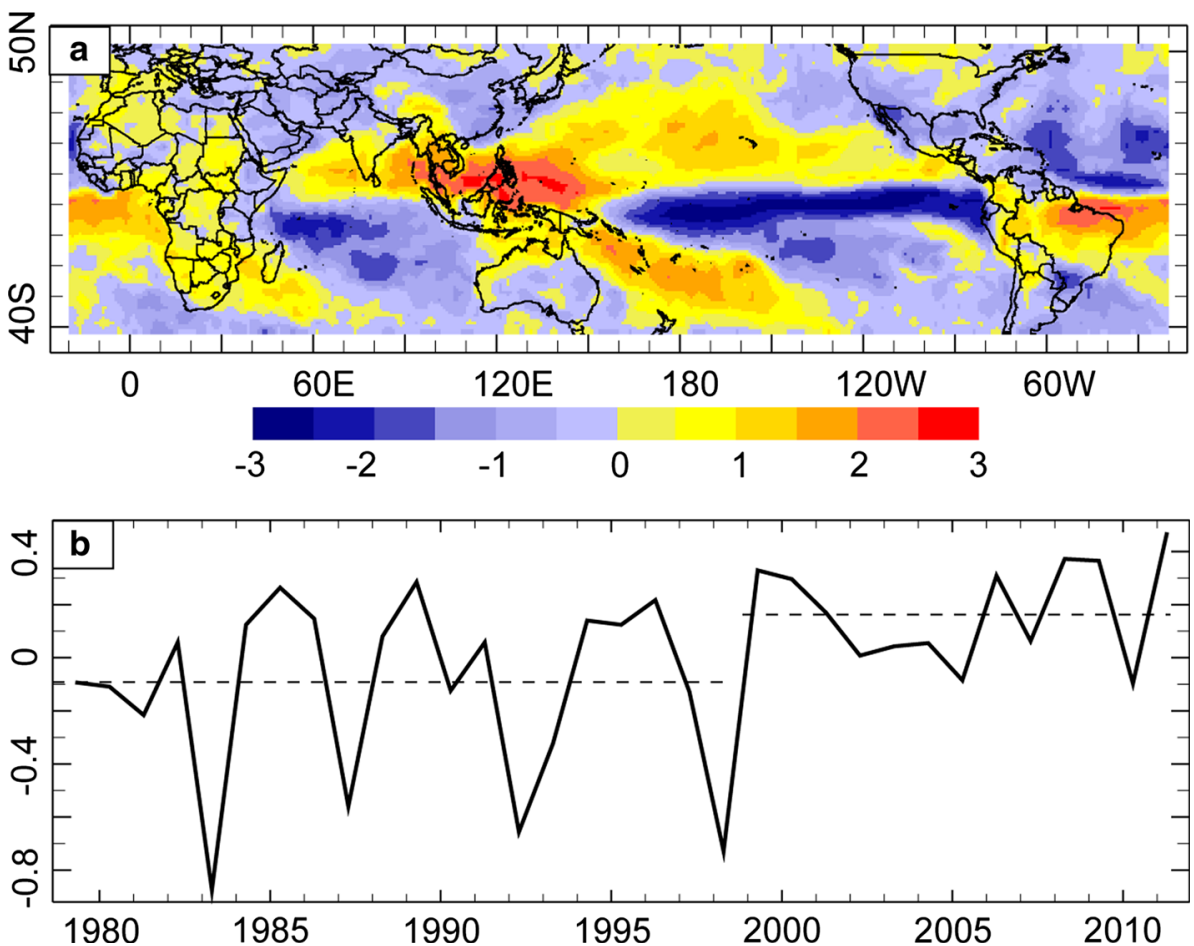

(not shown), the overall loading patterns remain quite similar to those in Fig. 3 but with the relative magnitude of the loadings increased in tropical regions (where total variance is typically smaller). Overall, a pattern indicative of an increased SST gradient across the tropical Pacific is identified without the contribution from ENSO or global temperature trends, at least to the extent that they have been removed in our linear analysis.

The temporal behavior of the SST EOF loading patterns is shown by the PC time series in Fig. 3c. The MAM values for individual years for the leading PCs are plotted in the figure along with their respective 9-year moving averages. Not surprisingly, the PCs for the two domains are very highly correlated $(r=0.99)$ while both exhibit an upward shift in 1999. Other multidecadal shifts, most clearly seen in the moving average values, line up well with reported transitions in the PDO: around 1925, 1946 and 1976 (e.g., Mantua et al. 1997; Deser et al. 2004). The temporal correlation coefficient between our MAM residual SST PC for the Pacific domain and the Mantua et al. (1997) PDO index for MAM (data obtained from http:// jisao.washington.edu/pdo/PDO.latest) is $r=0.67$. Thus, the recent shift towards cooler conditions in the eastern Pacific indeed appears to be associated with multidecadal SST variability that is related to the PDO. A similar analysis applied to the Pacific domain during other seasons of the year (not shown) revealed generally comparable spatial loading patterns for the EOFs and similar temporal shifts in the PCs in 1999, indicating the results for MAM apply more generally to other seasons. The thick, black line in Fig. 3c is the global average SST anomaly time series (used in the regression analysis to remove the global warming signal). It is interesting to note that the recent shift in SST conditions in 1999 towards cooler conditions in the eastern and central Pacific (and Indian Ocean as indicated by the sign of the loadings in Fig. 3b) appears slightly in advance of the recent leveling of the global average SST anomalies. A relationship between decadal variability in tropical Pacific SSTs and global temperatures has been reported previously (e.g., Bratcher and Giese 2002) and it may be playing a role in recent global temperature trends. The extent to which the recent shift and attendant large-scale wind anomaly pattern has contributed to a recently reported uptake of heat by the deep ocean (Balmaseda et al. 2013) remains an open question and one that is beyond the scope of the current study.

\subsection{Multidecadal shifts in MAM precipitation}

If the post-1998 changes in MAM precipitation shown in Fig. 1b are associated with multidecadal variations in SST in the Pacific, then it would be expected that regional precipitation patterns during the previous cold phase (1947-1976) would be similar. While previous studies have examined precipitation changes for different epochs of the PDO (Deser et al. 2004; Deser and Phillips 2006) they have mainly concentrated on the northern hemisphere cool season (typically NDJFM) or on regional versus global changes (Minobe 1997; Mantua et al. 1997). Here, multidecadal precipitation variations for MAM are 

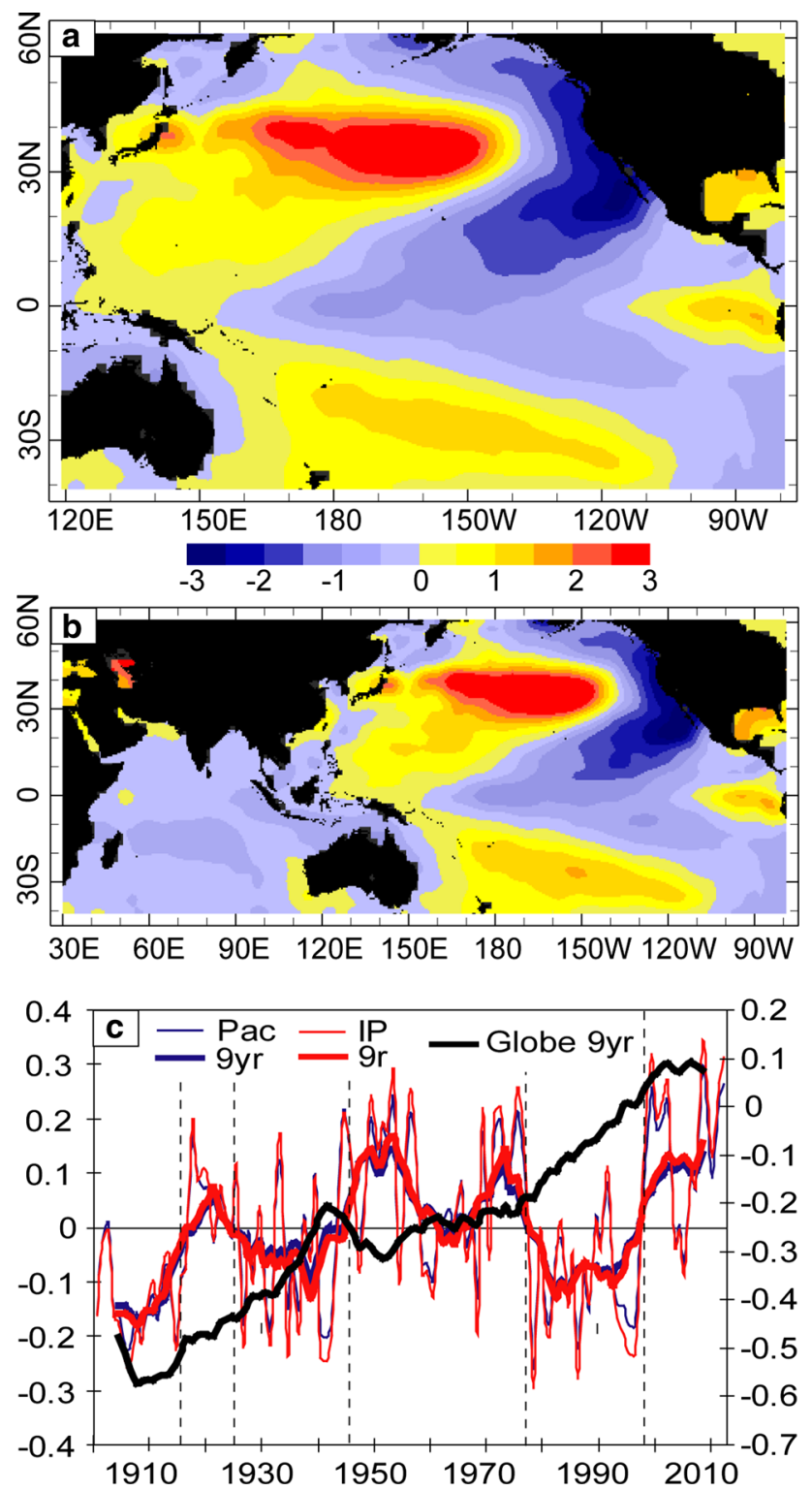

Fig. 3 a Loading pattern (dimensionless) of the leading EOF of the MAM residual SST data evaluated over the period 1900-2012 for the Pacific domain. b As in a but for a domain which also includes much of the Indian Ocean. c) Associated PC time series for the Pacific (blue) and Indo-Pacific (red) domains (left-scale) with thick lines indicating 9-year moving average values. The thick black line indicates the global $\left(55^{\circ} \mathrm{S}-55^{\circ} \mathrm{N}\right)$ average MAM SST anomaly (using a 1971-2000 base period) with a 9-year moving average applied (right-scale, in deg. C). The dashed vertical lines indicate the dates of zero crossings of the PC time series for the Pacific domain

examined by analyzing detrended precipitation values in the station-based GPCC dataset over the period 1940-2010. Plotted in Fig. 4 are the differences between average MAM precipitation for 1999-2010 (Fig. 4a) and 1947-1976 (Fig. 4b) from the MAM average for 1977-1998. The two figures show a number of coherent regional anomaly patterns in common for the two periods, with the pattern correlation over the domain shown being equal to 0.78 . Figure $4 \mathrm{c}$ indicates only those regions where the average of the pooled data for the years 1947-1976 and 1999-2010 is statistically different from the 1977-1998 period average (at $p<0.10$ ). Note that the recent drying in East Africa reported by LD in the post- 1998 period is a common feature during the previous Pacific cold phase, as are relative dry conditions in central-southwest Asia, the southwestern US, coastal southeastern China and portions of northeastern Australia. Regions with statistically significant wetter conditions include northern South America, a zonal band extending from southern India eastward to the Philippines and portions of the Maritime Continent, northern Australia and parts of southern Africa. Multidecadal SST variability in the Pacific is thus clearly linked to a global-scale pattern of precipitation variability during the MAM season. As noted earlier, the recent multidecadal shift in Pacific SSTs is also identified in other seasons of the year, thus it is quite likely that there are regional precipitation pattern shifts in seasons other than MAM as well. An investigation of those shifts, however, goes beyond the scope of the current investigation.

\subsection{Atmospheric circulation changes associated with the recent shift}

Investigations of the 1976-1977 shift in the Pacific have emphasized changes in the intensity and to some extent, location, of the Aleutian low during the boreal cold season and its connection to an anomalous stationary wave train similar to the Pacific North American (PNA) pattern (Tenberth and Hurrell 1994; Mantua et al. 1997; Deser et al. 2004). Very similar results were found in studies that first removed the ENSO signal from the cool season upperlevel geopotential height field either by a simultaneous linear regression approach or temporal filtering (Zhang et al. 1996, 1997). It is not clear, however, that similar results will be obtained for the recent shift during the MAM season. For example, climatologically the Aleutian low is weakening as the subtropical ridge in the eastern North Pacific begins to strengthen during MAM. And while Wang et al. (2012), for example, do identify some circulation anomalies in the vicinity of the Aleutians in boreal spring related to the PDO, they did not examine global scale changes in the atmospheric circulation.

Here, to examine how the low-level atmospheric circulation has changed following the recent shift during the MAM season, the anomalous $850 \mathrm{hPa}$ wind field was analyzed using the R2 and $20 \mathrm{CR}$ datasets. A joint EOF analysis was performed on the horizontal wind component anomalies (computed relative to a 1979-1998 base period) in both datasets. As the composite wind anomalies shown in Fig. 1b showed little in the way of statistically significant changes in the low-level winds over much of the 
Fig. 4 a Difference in average MAM precipitation for 1999-2010 minus 1977-1998 (in $\mathrm{mm} / \mathrm{month}$ ). b As in $\mathbf{a}$, but for 1947-1976 minus 1977-1998. The pattern correlation between $\mathbf{a}$ and $\mathbf{b}$ is 0.78 . c Statistically significant $(p<0.10)$ differences in MAM precipitation (plotted in $\mathrm{mm} /$ month) for pooled values covering 1947-1976 and 1999-2010 minus the 1977-1998 average
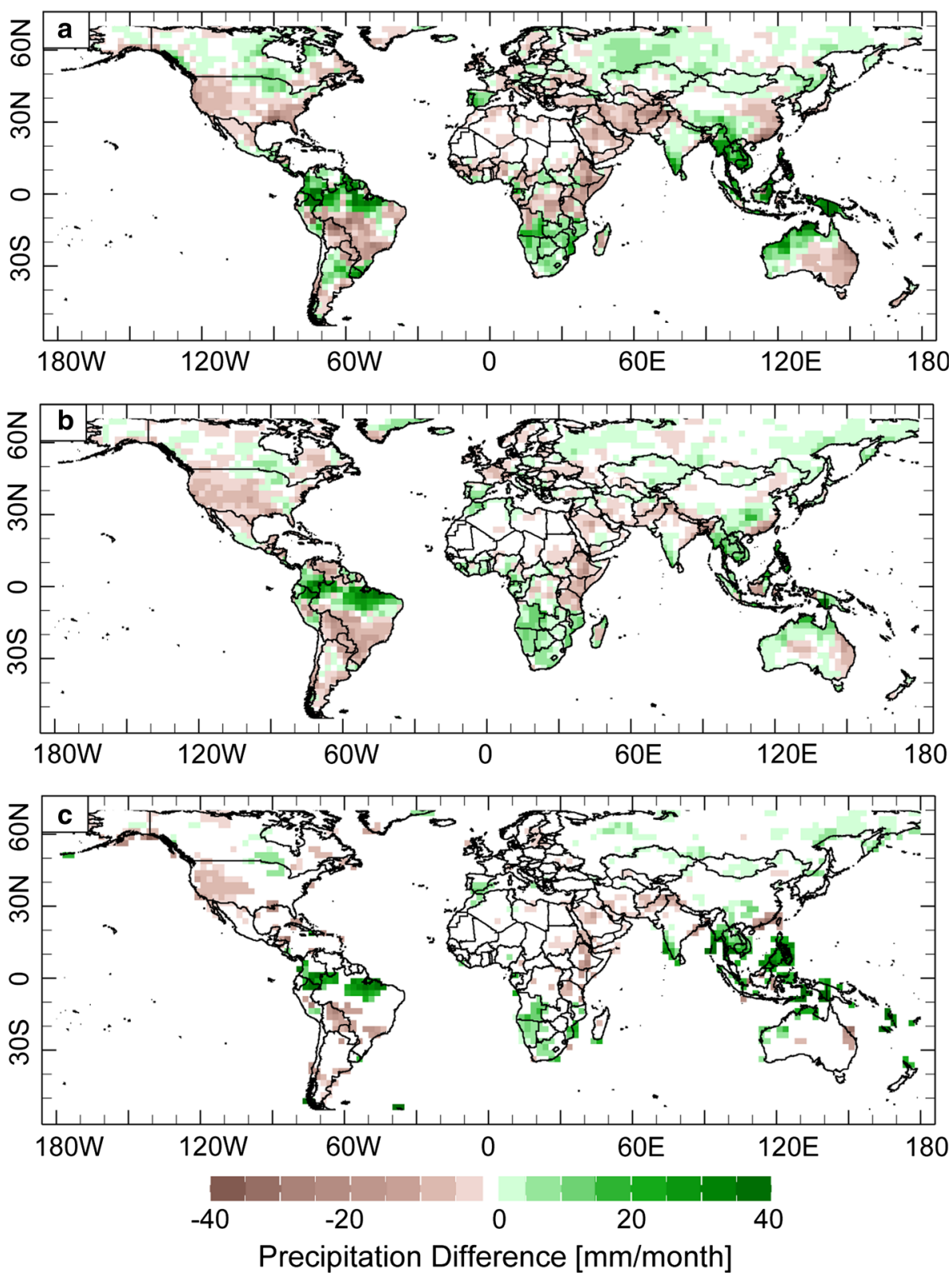

Atlantic during the post-1998 period, the domain for the EOF analysis was restricted to the Pacific and Indian Ocean basins. Figure 5a shows the loading patterns expressed as a vector field for R2 (period of analysis 1979-2012) with the associated result for 20CR (1930-2008) provided in Fig. 5b. Although in EOF analysis the sign of the loadings is arbitrary, as plotted in Fig. 5 the main features of the loadings are consistent with the sign of the composite wind anomalies in Fig. 1b, and in the following discussion the sign of the circulation anomalies will be in that context.

Consistent with composite values, in both R2 and 20CR the leading EOF (accounting for 19.0 and $15.1 \%$ of the variance respectively) indicates an anomalous anticyclonic circulation southeast of the Aleutians. Examination of the evolution of this feature in $\mathrm{R} 2$ based on monthly composites averaged over the period 1999-2012 (not shown) found that this anomalous circulation is identified during each month, revealing an accelerated weakening of the climatological Aleutian low during March and an anomalous anticyclonic circulation located on the northern flank of the climatological subtropical high in the eastern North pacific during the subsequent months of April and May. Another consistent feature across the two datasets for the EOF analysis in Fig. 5 is the enhanced easterlies across the central and western equatorial Pacific and anomalous westerlies across the northern Indian Ocean. Similar to the composite $850 \mathrm{hPa}$ wind anomalies in Fig. 1b over the western Indian Ocean, the EOF loadings indicate a cross equatorial flow off the coast of East Africa and an extended band of southeasterlies south of the equator seen most 
Fig. 5 a The leading loading pattern expressed as vectors obtained from a joint EOF analysis of anomalous MAM $850 \mathrm{hPa}$ winds in $\mathrm{R} 2$ over the period 1979-2012

(dimensionless, sample vector magnitude in lower-right). b As in a, but based on 20CR data for the period 1930-2008.

c Associated PC time series for R2 (red) and 20CR (black).

Thick lines represent values from a 9-year moving average and the dashed lines represent shift dates in multidecadal variations of Pacific SST as shown in Fig. 3

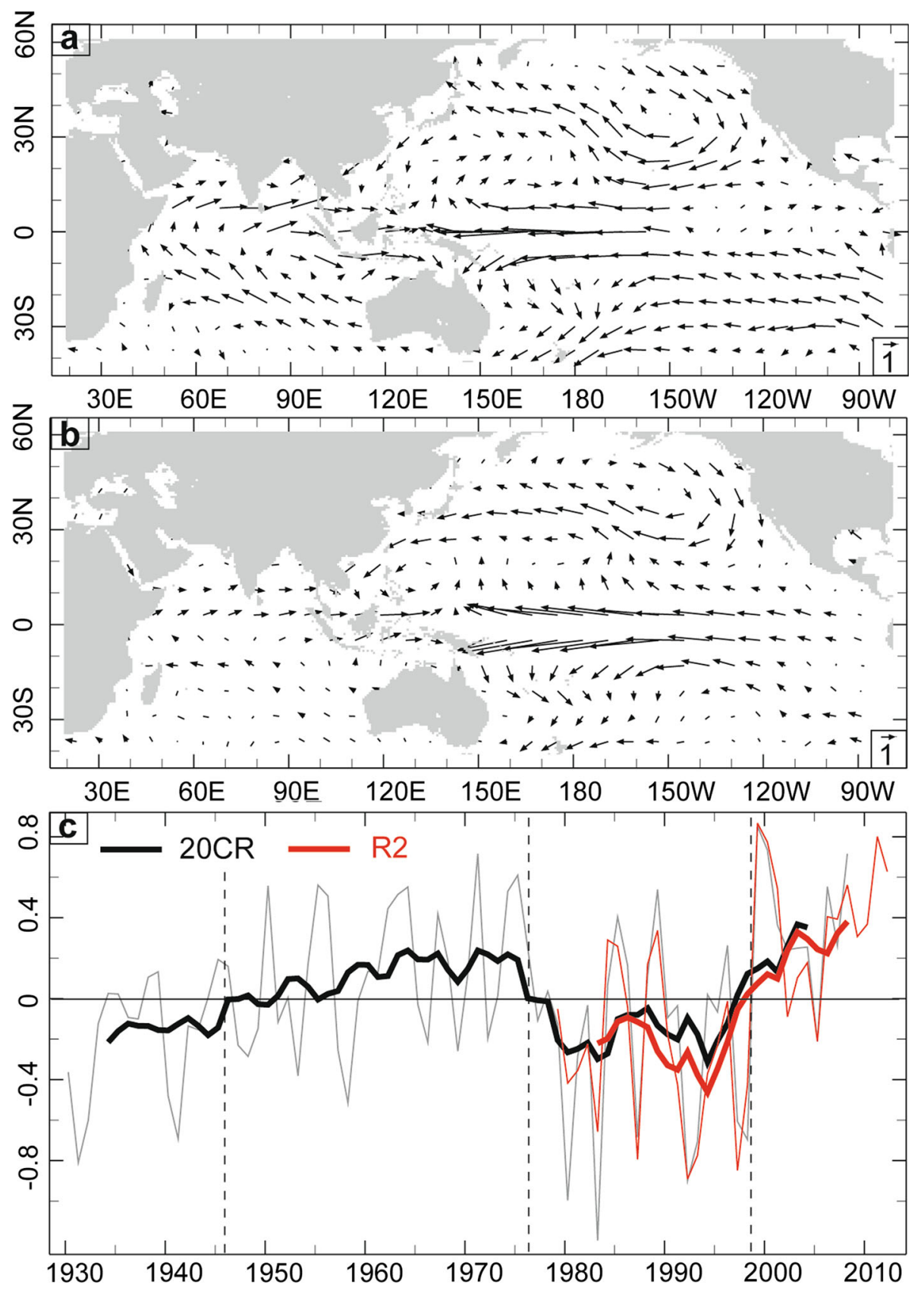

clearly in R2 but also present in 20CR. This feature was noted by LD and a recent study by Xiang and Wang (2013) identifies similar $850 \mathrm{hPa}$ wind anomaly features over the Indian Ocean region during the month of May in their examination of the advanced onset of the Asian summer monsoon in recent years. Xiang and Wang (2013) interpret the anomalous westerlies over the northern Indian Ocean as resulting from Rossby waves emanating from the enhanced convection in the western tropical Pacific and their interaction with the spatially-varying mean background wind field. Consistent with the results here and in LD, they also indicate an abrupt change in the wind field over the Indian
Ocean in 1999. Other noteworthy features in Fig. 5 include an implied, anomalous convergence into the SPCZ region east of Australia, which is consistent with the composite wind anomalies and enhanced precipitation there in the post-1998 period (cf. Fig. 1b, c) and the indication of an anomalous cyclonic circulation in the western tropical Pacific in both datasets, most clearly seen in the northern hemisphere.

The PC time series for the $850 \mathrm{hPa}$ wind field $\mathrm{EOF}$ analysis in R2 and 20CR are shown in Fig. 5c where a 9-year moving average has also been applied to both series. The time series for R2 and 20CR are highly correlated 
$(r=0.89)$ for the common period 1979-2008, with both showing an upward shift in 1999. The timing of other zero crossings for the $20 \mathrm{CR}$ data are consistent with the multidecadal shifts seen in the residual SST PC time series shown in Fig. 3c. Taken together, the analysis of the lowlevel circulation indicates multidecadal variability in the large-scale wind field, which post-1998 is very consistent with the composite wind field anomalies shown in Fig. 1b. In addition, the similarity of our 20CR results with those of Xiang and Wang (2013) for the post-1979 era over the Indian Ocean effectively extends their analysis further back in time, further supporting the suggestion of a multidecadal modulation of the onset date of the South Asian monsoon.

Post-1998 changes in global stationary waves were examined using the de-trended $200 \mathrm{hPa}$ geopotential height field in the R2 and 20CR datasets. Stationary waves were defined as the difference in the local geopotential height from zonal averaged values, with anomalies defined in Figs. $6 \mathrm{a}$ and $7 \mathrm{a}$ as the difference between average values for 1999-2012 (1999-2008 for 20CR) and 1979-1998. The grey shading in Figs. $6 \mathrm{a}$ and $7 \mathrm{a}$ indicates anomaly values that are statistically significant at $p<0.05$. In $\mathrm{R} 2$, an anomalous ridge extending from the Aleutians southeastward appears to be part of a wave train similar to the PNA pattern, with an indication of wave propagation from the east-central Pacific into the southern hemisphere as well. In addition, another striking feature is the wave trains extending from the western Pacific into both hemispheres. These wave trains are associated with anomalous ridging in the western tropical Pacific which is consistent with the implied diabatic heating associated with enhanced precipitation there as well as the cyclonic circulation anomalies at $850 \mathrm{hPa}$ (cf. Fig. 5), which taken together indicate the expected baroclinic vertical structure. An anomalous ridge is located over the central-southwest Asia region, a feature similar to that described by Barlow et al. (2002) in their study of the protracted boreal winter season drought starting in 1998. A statistically significant, anomalous trough is seen in northern Russia in the vicinity of the Ural Mountains, a feature consistent with above average MAM precipitation shown in Fig. 4. However, when individual months are examined (not shown), this circulation feature weakens considerably during April and May, failing to reach statistical significance in these latter months. Generally similar features were identified in 20CR.

To examine the time-varying nature of the $200 \mathrm{hPa}$ anomalous stationary waves in R2 and 20CR, an EOF analysis was applied to the standardized, anomalous values with the loadings for the leading pattern (accounting for $15.4 \%$ of total variance) shown in Figs. $6 \mathrm{~b}$ and $7 \mathrm{~b}$. The loadings generally align closely with the main features of the composite difference in Figs. 6a and 7a, a notable exception being the lack of an anomalous circulation in the vicinity of the Urals in Russia in both R2 and 20CR. There is again a suggestion of a PNA-like pattern and a related pattern in the southern hemisphere, as well as wave trains propagating eastward into both hemispheres from the western tropical Pacific. The associated PC time series (Figs. 6c and 7c) again show a prominent upward shift in 1999 , with the difference between means for the periods 1979-1998 and 1999-2012 in both R2 and 20CR being statistically significant at $p<0.01$ based on a 2-tailed $t$ test. Much of the interannual variability in the PC time series is associated with ENSO, for example, in R2 the temporal correlation with a Niño3.4 SST anomaly index is $\mathrm{r}=0.86$. The correlation between the PC time series for $\mathrm{R} 2$ and 20CR is $\mathrm{r}=0.85$. Overall, as found in previous studies, changes in the atmospheric circulation associated with decadal variability in Pacific SSTs shows some similarity to the behavior of ENSO, but operating on much longer time scales (Zhang et al. 1997).

\section{Model simulations and POGA experiments}

\subsection{Modeled MAM precipitation changes}

The ECHAM4.5 atmospheric general circulation model was evaluated to examine its ability to capture the main precipitation and circulation features associated with the post-1998 shift identified in the observational analyses. The first step was to compare differences in the ensemble average MAM precipitation for the period 1999-2011 versus 1977-1998. The result for the full simulations (24 ensemble member average) forced with global, observed SSTs is shown in Fig. 8a, where only statistically significant values $(p<0.10$ are plotted). The model's full simulations are able to reproduce many of the main features seen in Figs. 1 and 4, including drying over East Africa and central-southwest Asia and the western US. Wetter conditions are captured over northern South America, the SPCZ region and the western Pacific, although the latter region does not extend westward over the northern Indian Ocean as is the case in observations. The full simulations do not capture statistically significant drying in eastern Australia or the enhanced precipitation identified in observations over portions of southern Africa. The same analysis, but based on the 30 member ensemble average of the POGA runs is shown in Fig. 8b. The POGA runs also capture the main features seen in observations and actually do a better job than the full simulations in capturing the enhanced rainfall over the northern Indian Ocean and southern Africa and the drier conditions over southeastern China. The enhanced precipitation to the southwest of Mexico in the eastern tropical Pacific in the POGA runs is much stronger than in the observations. 
Fig. 6 a Composite differences in $200 \mathrm{hPa}$ stationary waves for 1999-2012 minus 1979-1998 (in gpm). Grey shading indicates statistically significant $(p<0.05)$ differences.

b Leading loading pattern obtained from an EOF analysis of the standardized stationary wave anomalies (1979-1998 base period) at $200 \mathrm{hPa}$ in $\mathrm{R} 2$ (dimensionless) for the period 1979-2012. c Associated PC time series where the horizontal, dashed lines indicate mean values for the two periods
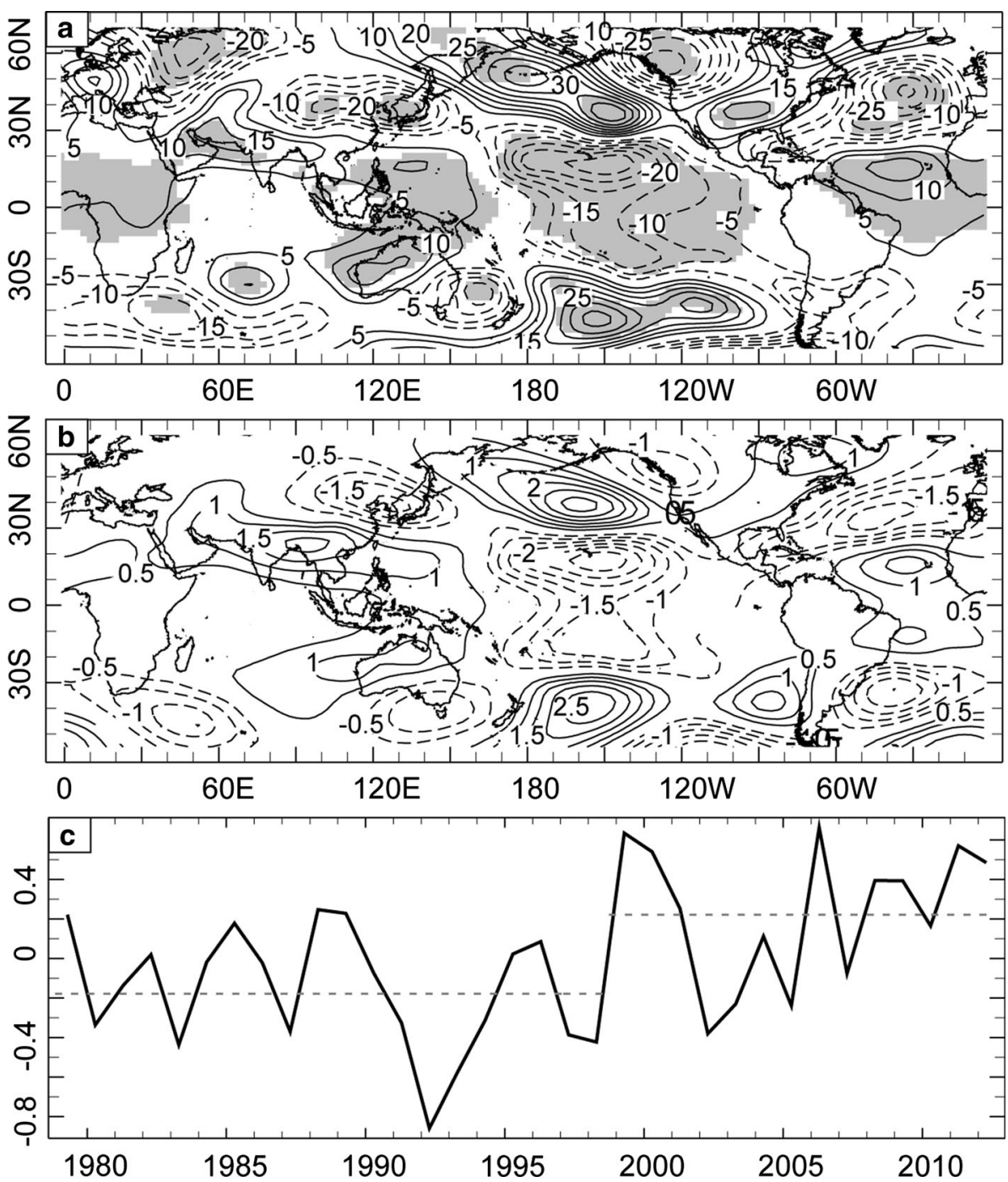

Overall, the excellent performance of the POGA experiments in generating most of the prominent precipitation features observed around the globe following the 1999 shift indicates the fundamental role of tropical Pacific SSTs in forcing these regional patterns. This result is reinforced by the isolated basin model experiments of LD and by the fact that, although SSTs in the slab ocean model outside of the tropical Pacific were allowed to vary in the POGA runs here, they did not depart substantially from climatology across the Indian and Atlantic basins when averaged over the MAM season for the period 1999-2011 (not shown), with slight cooling generated in the eastern Indian Ocean and north tropical Atlantic and modest warming elsewhere.

To examine the time-varying behavior of modeled MAM precipitation, an EOF analysis was applied to the ensemble mean anomalies (1977-1998 base period) in both the full simulations and POGA runs for the domain $40^{\circ} \mathrm{S}-55^{\circ} \mathrm{N}$. The loadings for the leading EOF patterns (explaining
$27.8 \%$ of the total variance in the full simulations; $35.4 \%$ in POGA runs) are shown in Figs. 9a and 9b. The loading patterns align well with each other and those based on observations (Fig. 2). The PC time series for the full simulations and POGA runs (Fig. 8c) are highly correlated $(r=0.97)$ and both the full simulations and POGA runs exhibit an upward shift in 1999. The difference between the mean values in the PC time series for both the full simulations and POGA runs for the pre- versus post-1998 period is statistically significant at $p<0.1$ for both sets of runs. Although statistically significant, this is not as strong a shift as seen in observations (Fig. 2b) as the model has a propensity to react more strongly to individual ENSO events than is seen in the observations during the post-1998 period. Nonetheless, the POGA results in particular again show that forcing from the tropical Pacific is indeed sufficient for the ECHAM4.5 model to capture the main precipitation features associated with the recent multidecadal shift in the Pacific, including, at least to some extent, the shift itself. 
Fig. 7 As in Fig. 6, but based on the 20CR data for the period 1930-2008. The thick red line in panel $\mathbf{c}$ is for a 9-yr moving average and the dashed horizontal lines represent the mean values for $1977-1998$ and 1999-2008
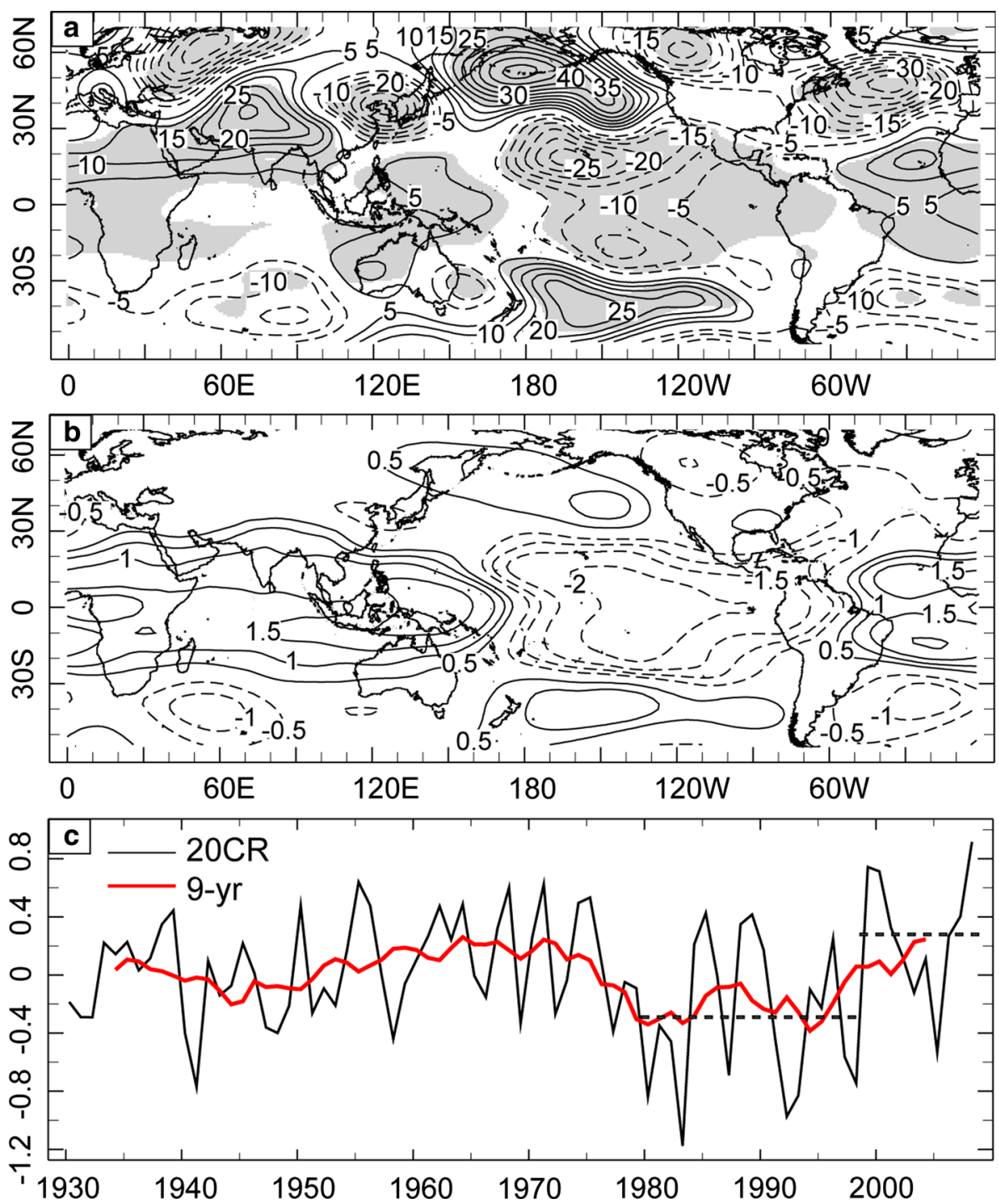

The role of the tropics in driving the response is consistent with previous modeling studies of the 1976-77 shift (Graham 1994; Huang et al. 2005; Deser et al. 2004).

\subsection{Modeled atmospheric circulation changes}

Similar to the analysis shown in Fig. 5, which was based on Reanalysis products, joint EOFs were computed for the $850 \mathrm{hPa}$ anomalous (1977-1998 base period) wind component fields in the ECHAM4.5 full simulations and POGA runs. The loadings of the leading EOF patterns (accounting for 52.8 and $55.3 \%$ of the total variance, respectively) are shown in Figs. 10a and 10b. The results over the Pacific are generally similar for both sets of runs, which capture the main features found in observations. The full simulations and POGA runs both capture the observed, anomalous easterlies across the central and western Pacific, an anomalous anticyclonic circulation in the vicinity of the
Aleutians, and anomalous westerlies across the northern Indian Ocean, the latter seen most strongly in the POGA runs. The associated PC time series (Fig. 10c) are very highly correlated $(r=0.98)$, with each showing a shift in 1999 (difference between respective mean values significant at $p<0.10$ ) although the model full simulations and POGA runs again both exhibit more temporal variability associated with ENSO than is seen in observations.

Finally, the anomalous $200 \mathrm{hPa}$ stationary wave patterns were examined in the model's full simulations and POGA runs in a manner similar to what is presented in Fig. 6 for R2. To emphasize the role of the tropical Pacific, Fig. 11a shows the composite anomalous stationary wave pattern computed as the difference between the MAM means for 1999-2011 and 1977-1998 in the POGA runs. The grey shading in the figure again indicates statistical significance ( $p<0.10$ based on a two-tailed $t$ test). The observed wave patterns from the central Pacific into both hemispheres are 
Fig. 8 a Difference in MAM precipitation between mean values for the periods 1999-2011 and 1977-1998 (in $\mathrm{mm} /$ day) based on full simulations from the ECHAM4.5 atmospheric model. Only statistically significant $(p<0.10)$ values are plotted based on a $t$ test. b As in $\mathbf{a}$, but for the POGA runs of the model forced only with observed SSTs in the tropical Pacific
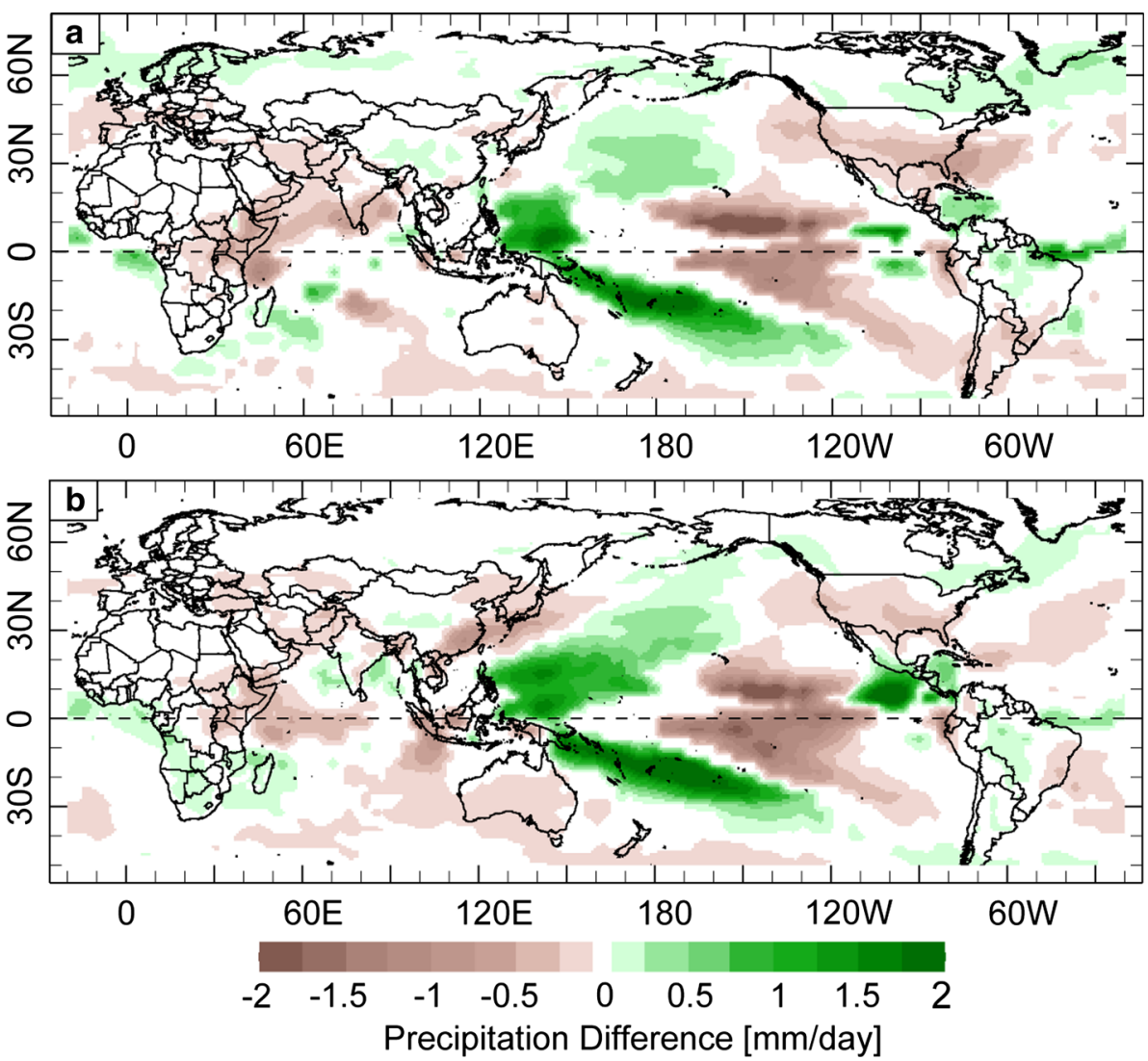

generally reproduced, as are the observed wave trains emanating from the western tropical Pacific into both hemispheres. An anomalous ridge is generated over central-southwest Asia, consistent with observations there (this feature is statistically significant at $p<0.10$ in this region based on a one-tailed test). The observed wave pattern over the Atlantic (see Fig. 6) is not captured in the POGA runs, suggesting that the diabatic heating associated with the anomalous rainfall near the equator in the observations may play a role in its forcing. This suggestion is based on the fact that the ECHAM4.5 full simulations (not shown) do exhibit a generally similar Atlantic wave pattern, though much weaker than in observations.

The loadings of the leading EOF pattern (accounting for $47.3 \%$ of the total variance) of the standardized anomalous stationary waves in the POGA runs are shown in Fig. 11b. The main features of the composite differences in Fig. 11a are generally seen, including the western Pacific wave trains into both hemispheres. The associated PC time series (Fig. 11c) does indicate an upward shift in 1999, with the difference between means for 1999-2011 and 1977-1998 statistically significant at $p<0.10$. As with the EOFs for $850 \mathrm{hPa}$ wind anomalies, the stationary wave response during ENSO events is stronger than in observations. Overall, however, with the notable exceptions of the Atlantic and northern Russia region near the Urals, the response of the climate model to observed MAM SST forcing from the tropical Pacific captures many of the main features of the observed, anomalous $200 \mathrm{hPa}$ stationary waves associated with the climate shift in 1999. This includes the shift itself.

\section{Summary and conclusion}

Observationally-based analyses and reanalysis products have been used to document a multidecadal shift in Pacific SSTs in 1998-1999 and associated atmospheric changes that are akin to the shift of 1976-1977. Emphasis is on the 3-month season of MAM, which has received only modest attention from previous investigators examining related multidecadal SST variations. The motivation for the study was to examine in greater detail the abrupt decline in MAM East African rainfall reported by LD that occurred in 1999 in order to view those results in a global domain and on multidecadal timescales. An EOF analysis of the residual anomalies of SSTs since 1900, determined by removing the (simultaneous) effect of ENSO and the global warming signal from the data by linear regression, revealed a loading pattern in the Pacific generally similar to the PDO. The associated PC time series shows a shift in 1999 indicative of, among other features, a change in the background state 
Fig. 9 a Loading pattern (dimensionless) of the leading EOF for MAM precipitation anomalies (1977-1998 base period) in the full ECHAM4.5 simulations for the period 1977-2012. b As in a, but for the POGA runs which extend from 1977-2011. c Associated PC time series for full simulations (red) and POGA (blue). Dashed lines indicate mean values for the two periods (which are nearly identical for both sets of runs over the two periods)
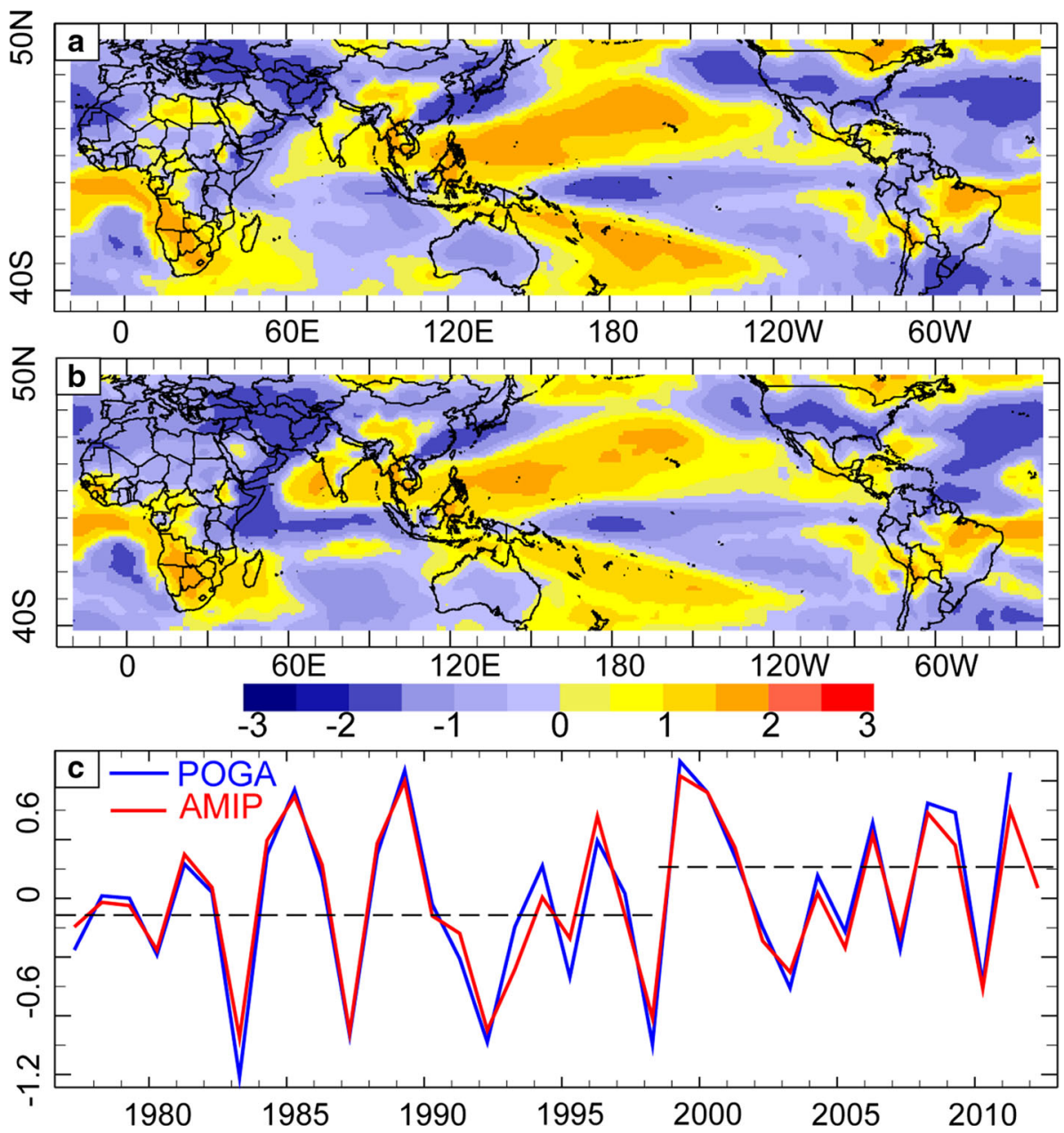

of Pacific SSTs towards cooler than average conditions in the east-central tropics. A composite difference of the full SST field in fact shows an average cooling of over $0.5^{\circ} \mathrm{C}$ for the period 1999-2012 relative to 1977-1998 in that region. The PC time series of the residual SST EOF reveals earlier shifts in 1925, 1946 and 1976, which are all consistent with previously reported shifts in the PDO (e.g., Mantua et al. 1997).

As expected, the precipitation response to the 1999 shift in SST is large scale, with statistically significant changes in MAM season totals for the post-1998 period seen in multiple locations including drying over East Africa and central-southwest Asia, coastal regions of southeastern China, parts of northeastern Australia and the southwestern US. Drier conditions are also seen over the central Indian Ocean and the east-central Pacific Ocean. Wetter conditions include a zonally elongated band across the northern Indian Ocean extending from the eastern Arabian Sea eastward across southern India to the Philippines, the western tropical Pacific and northern South America. A southwestward displacement of the SPCZ is also indentified.
Atmospheric circulation changes during MAM at $850 \mathrm{hPa}$ associated with the recent shift are observed in both hemispheres and include an anomalous anticyclonic circulation southeast of the Aleutians, enhanced easterlies in the equatorial Pacific and subtropics in both hemispheres and anomalous westerlies across the northern Indian Ocean. This latter feature, also identified by LD, is consistent with an earlier onset of the South Asian monsoon in recent years (Kajikawa and Wang 2012; Xiang and Wang 2013), with Xiang and Wang (2013) suggesting it is forced by Rossby waves emanating from the anomalous rainfall in the western tropical Pacific. Near-surface wind changes in the tropical Pacific are generally similar to those reported by $\mathrm{Hu}$ et al. (2013). The PC time series associated with a joint EOF analysis of the anomalous $850 \mathrm{hPa}$ wind components in 20CR going back to 1930 indicates a similar circulation pattern was present during the previous Pacific cool phase over the northern Indian Ocean, further supporting the notion of a decadal modulation of South Asian summer monsoon onset. At $200 \mathrm{hPa}$, anomalous stationary wave features included a PNA-like pattern in the northern hemisphere, with suggested wave propagation from the 
Fig. 10 a As in Fig. 5 but applied to the ECHAM4.5 $850 \mathrm{hPa}$ wind anomaly field. b As in a, but based on the POGA runs. c Associated PC time series with dashed lines again representing mean values for the two periods (nearly identical values for simulations and POGA runs)
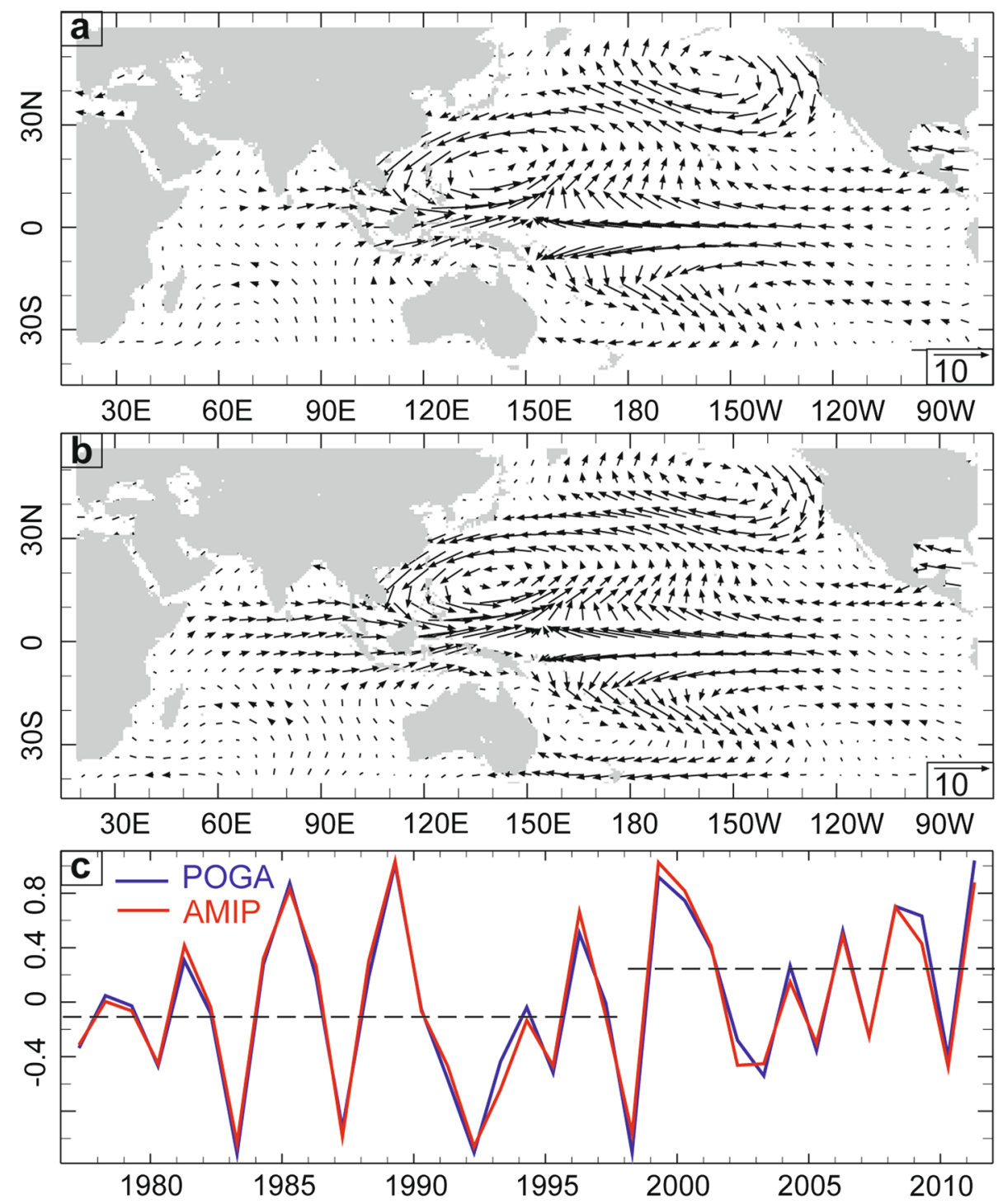

east-central Pacific region into the southern hemisphere as well. An anomalous wave train emanating from the western tropical Pacific into both hemispheres is also identified, most likely forced by the anomalous rainfall and associated diabatic heating in the western tropical Pacific. The PC time series associated with the EOF analyses of both the $850 \mathrm{hPa}$ wind field and $200 \mathrm{hPa}$ anomalous stationary waves both show an abrupt and statistically significant shift in 1999 in R2.

Model simulations using the ECHAM4.5 atmospheric general circulation model forced with globally observed SSTs ("full simulation") generally capture most of the observed precipitation and atmospheric circulation features associated with the recent shift. While both the full and POGA simulations tended to show greater interannaul variability associated with ENSO than in observations during the post-1998 period, based on an EOF analysis both sets of model experiments also produced a statistically significant shift during 1999 that is consistent with observations. POGA runs of the ECHAM4.5 forced with observed SSTs only in the tropical Pacific were also able to capture most of the main features associated with the recent shift and generated more realistic precipitation changes over the northern Indian Ocean and southern Africa compared with the full simulations. This result points to the fundamental role played by the tropical Pacific in forcing the observed atmospheric conditions, which is consistent with the conclusions drawn by previous studies examining the 1976-1977 shift (e.g., Graham 1994; Tenberth and Hurrell 1994; Deser et al. 2004).

Overall this study has documented a recent shift in Pacific SSTs, its connection with multidecadal variability and its influence on regional climate changes around the globe during the MAM season. While the SST loading 
Fig. 11 As in Fig. 6 but applied to the standardized, anomalous stationary waves from the POGA runs
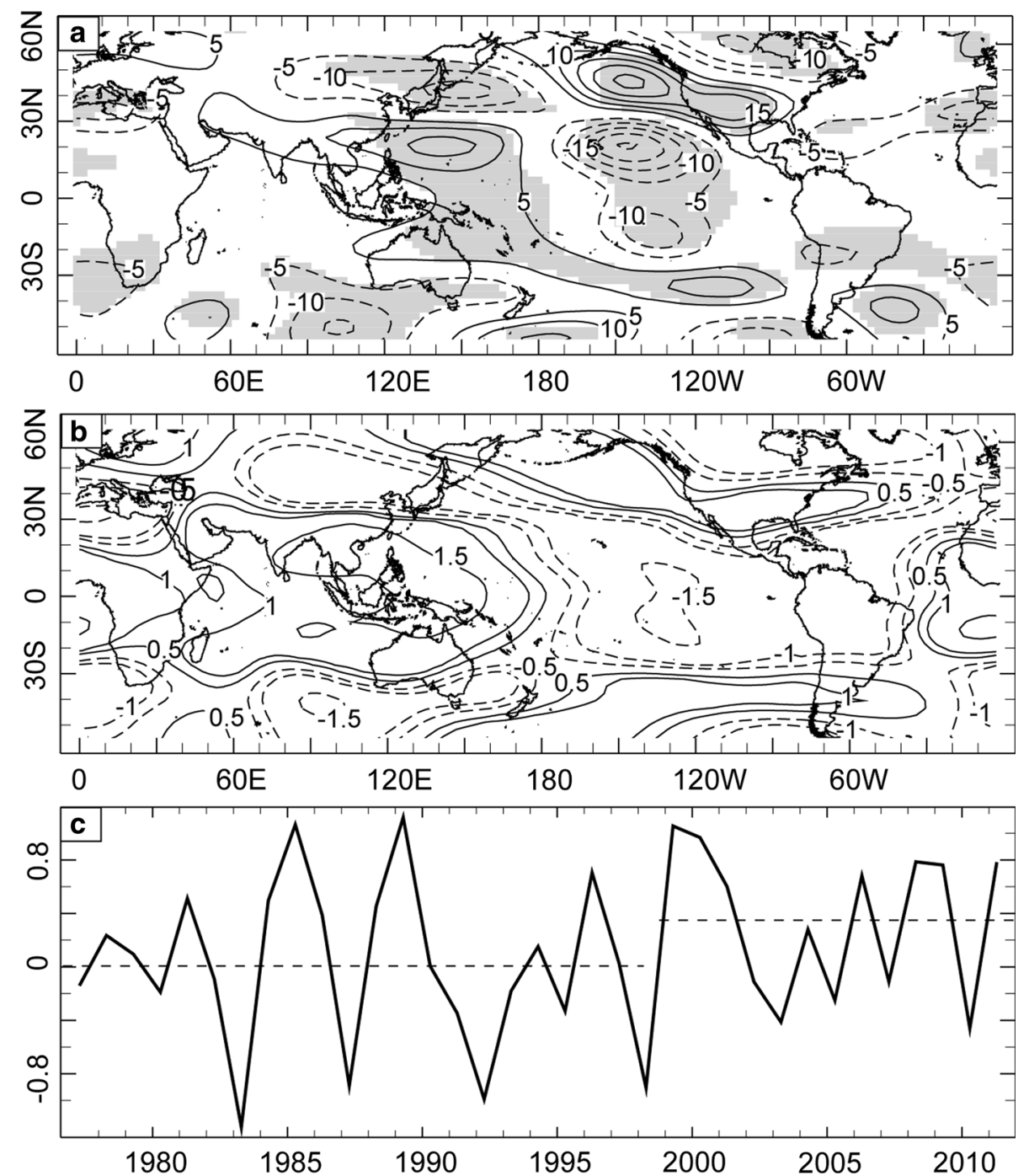

pattern identified in the EOF analysis of the residual SST field (i.e., after linearly removing ENSO and the global warming signal) resembles the behavior of the PDO, emphasis is not placed here on strict definitions of low frequency patterns of Pacific SSTs. The results presented would also map onto the interdecadal Pacific Oscillation (IPO) as described by Power et al. (1999), for example. And regardless of the analysis method used to identify it, we do not address the issue of causality of the observed, multidecadal variability and the recent associated shift. Causality is a fundamental question that goes beyond the scope of this study, with multiple hypotheses put forward in the scientific literature. On the one hand, a null hypothesis positing that such variability can be explained as red noise processes alone, including the reddening of the ENSO signal (Newman et al. 2003) has been advanced, while alternatively, various physical mechanisms have also been suggested, many contained in the recent review by Liu (2012). From a practical perspective, however, there is useful information in recognizing that the recent shift has occurred, having consequences for regional precipitation variability in several regions of the globe.

As the original motivation for the study was to examine in greater detail the abrupt decline in MAM East African rainfall in 1999, here the observational evidence, climate model full simulations and POGA run experiments all support the conclusion that this recent decline is directly related to multidecadal Pacific SST variability, with the forcing coming from the tropical Pacific. More generally, further work is needed to elucidate the physical mechanisms at work in generating the regional climate variations that have occurred around the globe during the post-1998 period.

Acknowledgments The authors would like to thank Michael Tippett for his assistance with the development of the residual SST data fields and Benno Blumenthal for the IRI Data Library. In addition, we thank the anonymous reviewers for their helpful comments. This work was supported by grants from the National Oceanic and Atmospheric Administration (NOAA grant NA05OAR4311004) and the National Aeronautics and Space Administration (NASA grant 
NNX12AR39G). Any opinions, findings, and conclusions or recommendations expressed in this material are those of the authors and do not necessarily reflect the views of NOAA or NASA.

Open Access This article is distributed under the terms of the Creative Commons Attribution License which permits any use, distribution, and reproduction in any medium, provided the original author(s) and the source are credited.

\section{References}

Balmaseda MA, Trenberth KE, Kallen E (2013) Distinctive climate signals in reanalysis of global ocean heat content. Geophys Res Lett 40:1-6. doi:10.1002/grl.50382

Barlow M, Cullen H, Lyon B (2002) Drought in Central and Southwest Asia: la Niña, the Warm Pool, and Indian Ocean Precipitation. J Climate 15:697-700

Bond NA, Overland JE, Spillane M, Stabeno P (2003) Recent shifts in the state of the North Pacific. Geophys Res Lett 30:2183. doi:10. 1029/2003GL018597

Bratcher AJ, Giese BS (2002) Tropical Pacific decadal variability and global warming. Geophys Res Lett 29. doi:10.1029/2002GL015191

Chavez FP, Ryan J, Lluch-Cota SE, Niquen M (2003) From anchovies to sardines and back: multidecadal change in the Pacific Ocean. Science 299:217-221

Compo, Gilbert P, Sardeshmukh PD (2010) Removing ENSO-related variations from the climate record. J Climate 23:1957-1978

Compo GP, Whitaker JS, Sardeshmukh PD, Matsui N, Allan RJ, Yin $\mathrm{X}$, Gleason BE, Vose RS, Rutledge G, Bessemoulin P, Bronnimann S, Brunet M, Crouthamel RI, Grant AN, Groisman PY, Jones PD, Kruk M, Kruger AC, Marshall GJ, Maugeri M, Mok HY, Nordli O, Ross TF, Trigo RM, Wang XL, Woodruff SD, Worley SJ (2011) The twentieth century reanalysis project. Q J Roy Meteorol Soc 137:1-28. doi:10.1002/qj.776

Deser C, Phillips AS (2006) Simulation of the 1976/77 climate transition over the North Pacific: sensitivity to tropical forcing. J Climate 19:6170-6180

Deser C, Phillips AS, Hurrell JW (2004) Pacific interdecadal climate variability: linkages between the tropics and the North Pacific during Boreal Winter since 1900. J Climate 17:3109-3124

Enfield DB, Mestas-Nunez AM, Trimble PJ (2001) The Atlantic multidecadal oscillation and its relation to rainfall and river flows in the continental U.S. Geophys Res Lett 28:2077-2080

Graham NE (1994) Decadal-scale climate variability in the tropical and North Pacific during the 1970s and 1980s: observations and model results. Climate Dyn 10:135-162

Hu ZZ, Kumar A, Ren HL, Wang H, L'Heureux M, Jin F-F (2013) Weakened interannual variability in the tropical Pacific ocean since 2000. J Climate 26:2601-2613

Huang HP, Seager R, Kushnir Y (2005) The 1976/77 transition in precipitation over the Americas and the influence of tropical sea surface temperature. Climate Dyn 24:721-740

Huffman GJ, Adler RF, Bolvin DT, Gu G (2009) Improving the global precipitation record: gPCP Version 2.1. Geophys Res Lett 36:L17808. doi:10.1029/2009GL040000

Kajikawa Y, Wang B (2012) Interdecadal change of the South China Sea summer monsoon onset. J Climate 25:3207-3218

Kanamitsu M, Ebisuzaki W, Woollen J, Yang SK, Hnilo JJ, Fiorino M, Potter GL (2002) NCEP-DOE AMIP-II Reanalysis (R-2). Bull Amer Meteor Soc 83:1631-1643
Liu Z (2012) Dynamics of interdecadal climate variability: a historical perspective. J Climate 25:1963-1995

Lyon B, DeWitt DG (2012) A recent and abrupt decline in the East African long rains. Geophys Res Lett 39:L02702. doi:10.1029/ 2011GL050337

Mantua NJ, Hare SR, Zhang Y, Wallace JM, Francis RC (1997) A Pacific interdecadal climate oscillation with impacts on salmon production. Bull Amer Meteor So. 78:1069-1079

McPhaden MJ, Lee T, McClurg D (2011) El Niño and its relationship to changing background conditions in the tropical Pacific. Geophys Res Lett 38:L15709. doi:10.1029/2011GL048275

Merrifield MA (2011) A shift in western tropical Pacific sea level trends during the 1990s. J Climate 24:4126-4138

Minobe S (1997) A 50-70 year climatic oscillation over the North Pacific and North America. Geophys Res Lett 24:683-686

Newman M, Compo GP, Alexander MA (2003) ENSO-forced variability of the pacific decadal oscillation. J Climate Lett 23:3853-3857

Peterson WT, Schwing FB (2003) A new climate regime in northeast pacific ecosystems. Geophys Res Lett 30:1896. doi:10.1029/ 2003GL017528

Power S, Casey T, Folland C, Colman A, Mehta V (1999) Interdecadal modulation of the impact of ENSO on Australia. Climate Dyn 15:319-324

Rayner NA, Parker DE, Horton EB, Folland CK, Alexander LV, Rowell DP, Kent EC and Kaplan A (2003) Global analyses of sea surface temperature, sea ice, and night marine air temperature since the late nineteenth century J Geophys Res 108 No D14 4407 10.1029/2002JD002670

Roeckner E, Arpe K, Bengtsson L, Christoph M, Claussen M, Dümenil L, Exch M, Giorgetta M, Schlese U and Schulzweida U (1996) The atmospheric general circulation model ECHAM-4 Model description and simulation of present-day climate. Report No 218 Max-Plank Institute für Meteorologie, Hamburg, 90 pp

Rudolf B, Schneider U (2005) Calculation of gridded precipitation data for the global land-surface using in situ gauge observations. In: Proceedings of the 2nd workshop of the international precipitation working group IPWG, Monterey, CA, October 2004, EUMETSAT, ISBN 92-9110-070-6, ISSN 1727-432X, pp 231-247

Smith TM, Reynolds RW (2003) Extended reconstruction of Global Sea surface temperatures based on COADS Data (1854-1997). J Climate 16:1495-1510

Tenberth KE, Hurrell JW (1994) Decadal atmosphere-ocean variations in the Pacific. Climate Dyn 9:303-319

Trenberth KE (1990) Recent observed interdecadal climate changes in the northern hemisphere. Bull Amer Meteor Soc 71:988-993

Wang H, Kumar A, Wang W, Xue Y (2012) Seasonality of the Pacific decadal oscillation. J Climate 25:25-38

Xiang B, Wang B (2013) Mechanisms for the advanced asian summer monsoon onset since the mid-to-late 1990s. J Climate 26:1993-2009

Xie P, Arkin PA (1997) Global precipitation: a 17-year monthly analysis based on gauge observations, satellite estimates and numerical model outputs. Bull Amer Meteor Soc 78:2539-2558

Zhang Y, Wallace JM, Iwasaka N (1996) Is climate variability over the North Pacific a linear response to ENSO? J Climate 9:1468-1478

Zhang Y, Wallace JM, Battisti DS (1997) ENSO-like Interdecadal Variability: 1900-1993. J Climate 10:1004-1020 